\title{
Transient Reduction of FMD-Response and L-Arginine Accompanied by Increased Levels of E-Selectin, VCAM, and ICAM after Prolonged Strenuous Exercise
}

\author{
Christoffer Nyborg 1,2,*, Helene Støle Melsom 1,2, Martin Bonnevie-Svendsen 1,2, Jørgen Melau 1,2,3®), \\ Ingebjørg Seljeflot ${ }^{1,4}$ and Jonny Hisdal ${ }^{1,2}$ \\ 1 Institute of Clinical Medicine, Faculty of Medicine, University of Oslo, 0318 Oslo, Norway; \\ h.s.melsom@studmed.uio.no (H.S.M.); martin.bonnevie@gmail.com (M.B.-S.); jorgen@melau.no (J.M.); \\ uxinlj@ous-hf.no (I.S.); jonny.hisdal@medisin.uio.no (J.H.) \\ 2 Department of Vascular Surgery, Oslo University Hospital, 0424 Oslo, Norway \\ 3 Department of Prehospital Care, Vestfold Hospital Trust, 3103 Toensberg, Norway \\ 4 Center for Clinical Heart Research, Department of Cardiology, Oslo University Hospital, 0424 Oslo, Norway \\ * Correspondence: nyborgchristoffer@gmail.com; Tel.: +47-971-76-129
}

check for

updates

Citation: Nyborg, C.; Melsom, H.S.; Bonnevie-Svendsen, M.; Melau, J.; Seljeflot, I.; Hisdal, J. Transient

Reduction of FMD-Response and

L-Arginine Accompanied by Increased Levels of E-Selectin, VCAM, and ICAM after Prolonged Strenuous Exercise. Sports 2021, 9, 86. https:// doi.org/10.3390/sports9060086

Academic Editor: Anthony Leicht

Received: 30 April 2021

Accepted: 16 June 2021

Published: 17 June 2021

Publisher's Note: MDPI stays neutral with regard to jurisdictional claims in published maps and institutional affiliations.

Copyright: (c) 2021 by the authors. Licensee MDPI, Basel, Switzerland. This article is an open access article distributed under the terms and conditions of the Creative Commons Attribution (CC BY) license (https:/ / creativecommons.org/licenses/by/ $4.0 /)$.

\begin{abstract}
We assessed endothelial function by flow-mediated dilatation (FMD), levels of the NOprecursor L-arginine, and markers of endothelial inflammation before, at the finish line, and one week after the Norseman Xtreme triathlon. The race is an Ironman distance triathlon with a total elevation of $5200 \mathrm{~m}$. Nine male participants were included. They completed the race in 14.5 (13.4-15.3) h. FMD was significantly reduced to $3.1(2.1-5.0) \%$ dilatation compared to 8.7 (8.2-9.3)\% dilatation before the race $(p<0.05)$ and was normalized one week after the race. L-arginine showed significantly reduced levels at the finish line $(p<0.05)$ but was normalized one week after the race. Markers of endothelial inflammation E-Selectin, VCAM-1, and ICAM-1 all showed a pattern with increased values at the finish line compared to before the race (all $p<0.05$ ), with normalization one week after the race. In conclusion, we found acutely reduced FMD with reduced L-arginine levels and increased E-Selectin, VCAM-1, and ICAM-1 immediately after the Norseman Xtreme triathlon. Our findings indicate a transient reduced endothelial function, measured by the FMD-response, after prolonged strenuous exercise that could be explained by reduced NO-precursor L-arginine levels and increased endothelial inflammation.
\end{abstract}

Keywords: FMD; endothelium; NO; inflammation; ironman; triathlon; E-selectin; VCAM-1; ICAM-1; L-arginine

\section{Introduction}

Flow-mediated dilatation (FMD) refers to the non-invasive assessment of endothelial function by studying the brachial artery's dilatation in response to increased blood flow [1]. The dilatation is endothelial-dependent [2] as increased shear forces from the blood activate mechanoreceptors in the endothelium [3], causing a predominantly NO-mediated relaxation of the arterial smooth muscles [4].

There are conflicting reports on the acute changes of FMD after exercise [5-16]. Still, a biphasic response has been proposed with an initial reduction in FMD after exercise with normalization within 24-48 h [17]. The initial FMD after exercise has also been shown to be inversely correlated to the exercise intensity [5]. However, there are few studies of how prolonged exercise affects the FMD-response $[6,16,17]$ and as far as we are aware there are no studies of FMD after any Ironman distance triathlon.

Prolonged strenuous exercise, as in Ironman distance triathlons, is known to cause a multitude of physiological changes that may influence the endothelial function, including a state of inflammation [18-20], increased cardiac- and muscular-damage biomarkers [18-22], 
and altered bioavailability of essential nutrients [23]. The main aim of the present study was to elucidate the acute effect of such extreme strenuous physical activity on vascular function.

We hypothesized that prolonged strenuous exercise affects the endothelium's inflammatory state and L-arginine's bioavailability, a precursor of the NO-signaling molecule [24]. To assess the endothelial inflammation, we measured E-selectin, ICAM-1, and VCAM-1, which are adhesion molecules expressed on the endothelial cells, stimulated by circulating inflammatory cytokines [25] and associated with endothelial damage [26].

\section{Materials and Methods}

\subsection{Study Population}

The study was conducted on participants in Norseman Extreme Triathlon 2019. The competition started with a jump from a ferry and a $3800 \mathrm{~m}$ swim in the Hardanger Fjord, followed by $180 \mathrm{~km}$ bicycling, with an elevation of more than $3000 \mathrm{~m}$ before finishing off with a $42.2 \mathrm{~km}$ run to Mt. Gaustatoppen (1883 $\mathrm{m}$ above sea level). The total elevation of the racecourse was $5200 \mathrm{~m}$.

The study was announced through an email to participants, and interested participants were sent more information about the study before they decided to enroll. The day before the race start, willing male participants who could perform a follow-up measurement at Oslo University Hospital one week after the race were included in the study. Male participants were selected because we could not control for menstrual cycles due to fixed race dates [27]. The participants were examined the day before the race, as soon as possible after crossing the finish line, and one week after the race.

The Regional Committee for Medical and Health Research Ethics in Norway (REC) approved all experimental measurements (reference: 2016/932), and the study was conducted according to the Declaration of Helsinki. All participants gave written informed consent.

\subsection{Flow-Mediated Dilatation (FMD)}

Participants were examined in the supine position after 20 min of rest. A standard blood pressure cuff was positioned around the right arm, two inches below the antecubital fossa, and the brachial artery was imaged 5-9 $\mathrm{cm}$ above the ante-cubital fossa. A linear array transducer probe (9 MHz, GE Vivid E95, GE Healthcare, Chicago, IL, USA) was used to acquire the brachial artery's images. The transducer was placed in a fixed position at the brachial artery and stabilized with a custom-made tripod. The cuff was inflated to a supra-systolic pressure $(230 \mathrm{mmHg})$ for $5 \mathrm{~min}$. B-mode images and pulsed doppler measurements of the right brachial artery were continuously captured for $190 \mathrm{~s}$, starting $10 \mathrm{~s}$ before the cuff was deflated. Automated analysis of end-diastolic diameters and blood velocities was performed in an edge-detecting software (Brachial analyzer, Medical Imaging Applications LLC, Coralville, IA, USA). FMD was calculated as the percentage increase in diameter from $10 \mathrm{~s}$ before cuff deflation to maximum dilatation post-occlusion. The maximum flow was calculated from blood velocities and diameter measurement as a measurement of stimuli.

\subsection{Blood Samples}

Venous blood samples were collected at all time points in vacuum containers with silica particles and gel separators. The blood was clotted for $30 \mathrm{~min}$ at room temperature, serum was separated by centrifugation at $2000 \times g$ for 10 min within $1 \mathrm{~h}$, and the serum was pipetted to separate freeze-tolerant containers. All samples were transported on ice to freezing storage with a temperature of $-80^{\circ} \mathrm{C}$. Commercial ELISA kits were used for VCAM-1, ICAM-1, and E-selectin (R\&D Systems Europe, Abingdon, Oxon, UK). Intra assay coefficients of variations (CVs) were $2.1 \%, 2.8 \%$, and $2.2 \%$, respectively. L-arginine was determined by high-performance liquid chromatography (HPLC) and pre-column derivatization with o-phthaldialdehyde (OPA) (Sigma Chemicals Co, St Louis, MO, USA). 


\subsection{Statistics}

Friedman's tests were applied to examine for any differences between the times of measurements for each test. Wilcoxon Signed-Rank Sum tests were applied as post hoc tests. A $p$-value of $<0.05$ was considered significant. All values are presented as median (1. quartile, 3. quartile). Statics was conducted in $\mathrm{R}$ ( $\mathrm{R}$ version 4.0.3, $\mathrm{R}$ Foundation for Statistical Computing, Vienna, Austria).

\section{Results}

\subsection{Subjects}

Nine male participants of the Norseman Xtreme Triathlon were included in this study. Complete sets of blood samples were collected in eight subjects. The subjects did not compete in any long-distance running or triathlon competition the week between the measurements. Characteristics of the subjects are given in Table 1.

Table 1. Characteristics of the subjects. Values are given as median (1. quartile, 3. quartile). $\mathrm{N}=9$; * Reported average weekly exercise last year. ${ }^{* *}$ Reported number of years competing in long-distance running or triathlons, marathon distance or above. All blood pressures were measured at rest before the race.

\begin{tabular}{|c|c|}
\hline Characteristic & Value \\
\hline Age (years) & $43(40-49)$ \\
\hline Weight (Kg) & $78(70.6-78.5)$ \\
\hline Height (m) & $1.81(1.74-1.83)$ \\
\hline Weekly endurance exercise ${ }^{*}(\mathrm{~h})$ & $16(12-18)$ \\
\hline Weekly strength exercise ${ }^{*}(\mathrm{~h})$ & $1(0-2)$ \\
\hline Completed Ironman triathlons (n) & $1(0-4)$ \\
\hline Completed marathons (n) & $5(1-7)$ \\
\hline Completed ultra-distance races (n) & $2(0-7)$ \\
\hline Years of competing ** $(y)$ & $7(5-10)$ \\
\hline Body mass index $\left(\mathrm{Kg} / \mathrm{m}^{2}\right)$ & $23.4(22.1-24.7)$ \\
\hline Systolic blood pressure (mmHg) & $127(125-130)$ \\
\hline Diastolic blood pressure (mmHg) & $73(70-78)$ \\
\hline Swim time $(\mathrm{h})$ & $1.1(1.0-1.3)$ \\
\hline Bike time $(\mathrm{h})$ & $7.0(6.4-7.3)$ \\
\hline Run time (h) & $5.9(5.3-6.2)$ \\
\hline Finish time $(\mathrm{h})$ & $14.5(13.4-15.3)$ \\
\hline
\end{tabular}

\subsection{Flow-Mediated Dilation (FMD)}

As seen in Figure 1, FMD was reduced at the finish line compared to baseline: 3.1 $(2.1-5.0)$ vs. $8.7(8.2-9.3), p<0.05)$. The FMD returned to baseline values one week after the competition ( $p=0.25$, compared to before start). There were no significant differences between arterial baseline diameters $(p=0.24)$ or maximum flow calculations $(p=0.10)$ between the time points. 


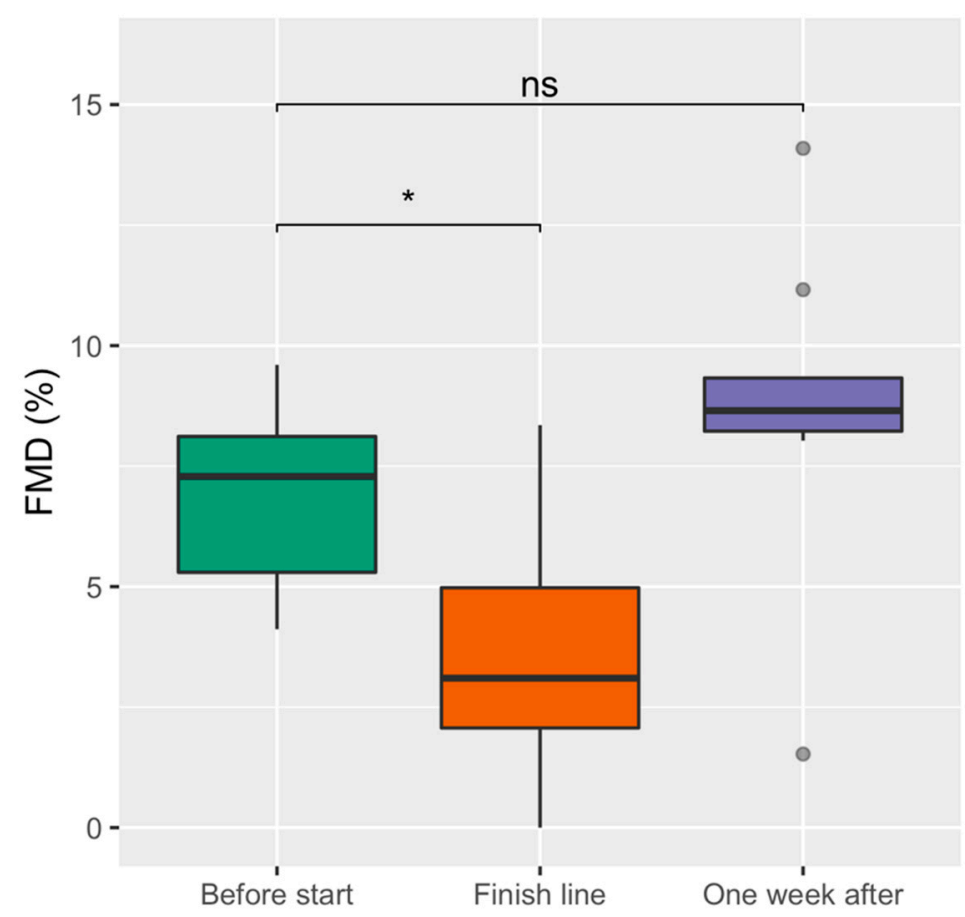

Figure 1. Flow-mediated dilatation (FMD) before the start, at the finish line, and one week after the race with two-sided post hoc Wilcoxon Signed-Rank Sum tests. The boxplots are drawn with a thick line as median; boxes are the interquartile range (IQR) from 1. quartile to 3. quartile; whiskers are maximum value within 1.5 times IQR; values above or below 1.5 times IQR are shown as outliers. * Indicates $p$-value $<0.05$ and ns a $p$-value $>0.05$. Friedman's Ranked Sum test showed a $p$-value $<0.05$.

\subsection{Biomarkers}

E-Selectin, VCAM-1, and ICAM-1 all showed a similar pattern with increased values at the finish line compared to before the race (all $p<0.05)$ and reduction one week after the race. E-selectin returned to baseline values one week after the race $(p=0.74)$. VCAM- 1 was reduced below baseline values one week after $(p<0.05)$. ICAM-1 showed a similar trend to VCAM-1, but levels after one week were not statistically significantly different from the baseline $(p=0.06)$. L-arginine showed significantly reduced levels at the finish line $(p<0.05)$ and was normalized one week after the race $(p=0.08)$. Full results for E-Selectin, VCAM-1, ICAM-1, and L-arginine are shown in Figure 2. Raw data are also made available in the Supplemental information as S1. 
A

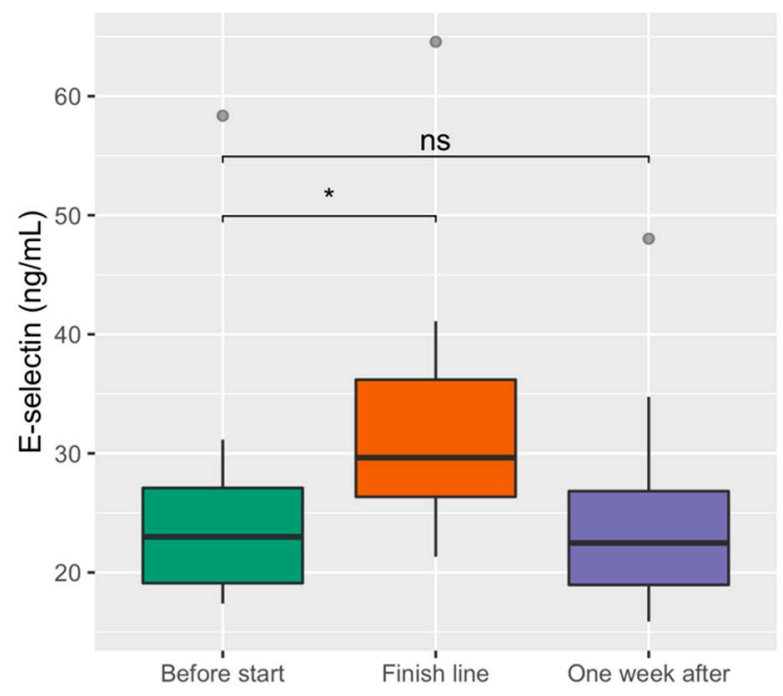

C

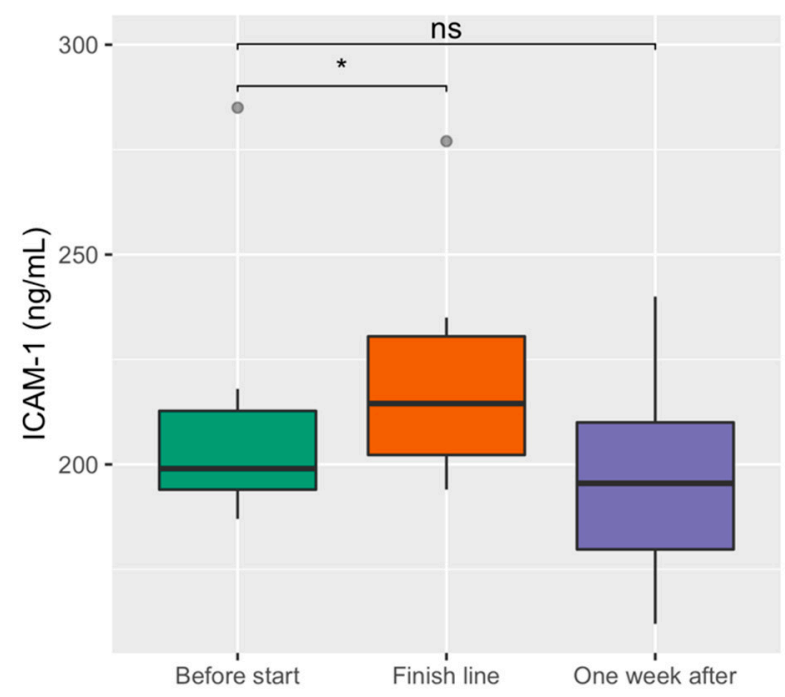

B

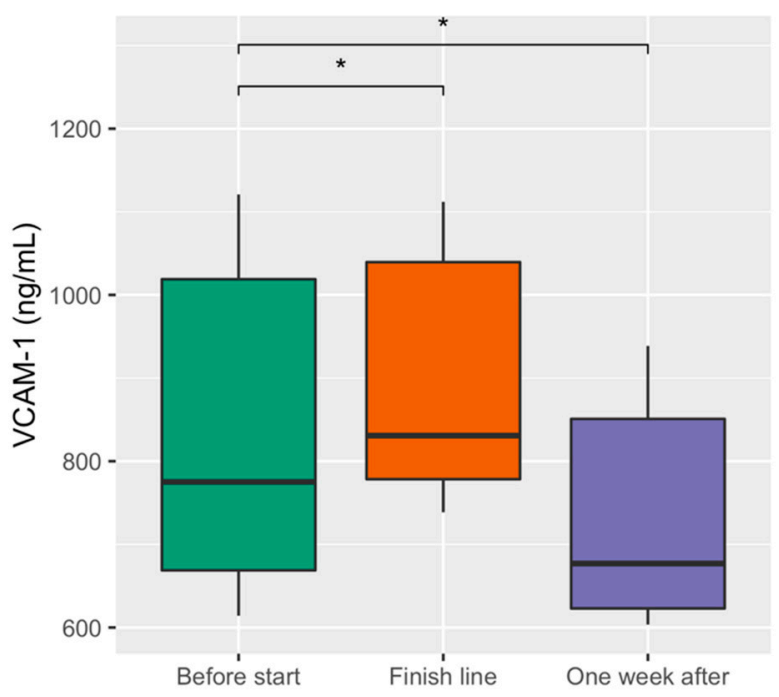

D

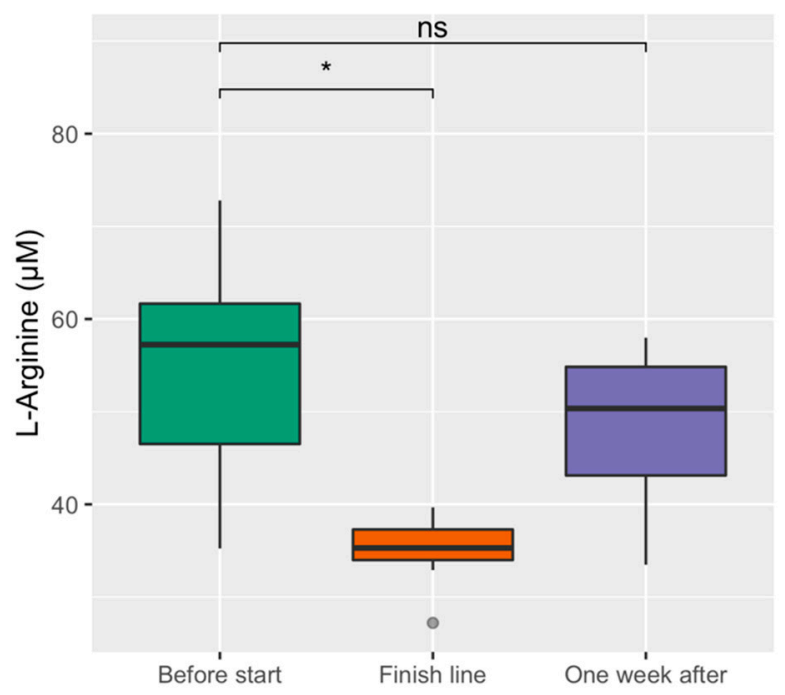

Figure 2. E-selectin (A), VCAM-1 (B), ICAM-1 (C), and L-Arginine (D) before the start, at the finish line, and one week after the race with two-sided post hoc Wilcoxon Signed-Rank Sum tests. The boxplots are drawn with a thick line as median; boxes are the interquartile range (IQR) from 1. quartile to 3. quartile; whiskers are maximum value within 1.5 times IQR; values above or below 1.5 times IQR are shown as outliers. * Indicates $p$-value $<0.05$ and ns a $p$-value $>0.05$. Friedman's Ranked Sum test for all the biomarkers showed a $p$-value $<0.05$.

\section{Discussion}

This study's main finding was that triathletes participating in the Norseman Xtreme triathlon showed a transient reduction in FMD-response immediately after the race. The FMD-response was normalized within one week after the competition. Secondly, we found corresponding reduced levels of the NO-precursor L-arginine after the race [24]. In addition, we observed increased levels of the endothelial inflammation markers, E-Selectin, VCAM-1, and ICAM-1, after the race [25]. The alterations in L-arginine, E-selectin VCAM-1, and ICAM-1 were all transient, like the changes in FMD.

Reports of changes in FMD after prolonged exercise are scarce. One study by Dawson et al. after the London Marathon in 2007 demonstrated a reduced femoral FMD but no significant changes in brachial FMD [6]. However, Dawson and Green, Cable, and Thijssen later proposed in a synthesis on effects of acute exercise on FMD in 2013 that FMD is acutely decreased immediately after exercise, followed by an improvement $1-24 \mathrm{~h}$ postexercise 
and normalization by 24-48 $\mathrm{h}$ [17]. Following this thesis, the measurements' timing could explain the lack of observed changes in systemic endothelial function measured by brachial FMD after the London Marathon. Simultaneously, reduced FMD in the femoral artery among the marathon runners indicates more long-lasting changes in the endothelial function in the conduit arteries supplying the lower body's active muscle bed [6]. In triathlons, the upper body muscles are used in swimming and partly statically during biking, causing active muscle usage in both legs and arms during the exercise event. The legs are most affected [28], but the use of the upper body causes the brachial artery to be subjectable to both local and systemic effects regarding increased blood flow and shear, in contrast to after a marathon where the brachial artery is mostly subjectable to systemic effects only.

Another potential explanation for the brachial FMD reduction after the Norseman Xtreme triathlon could be increased systemic inflammation after Ironman distance triathlons [19-22] compared to after marathons [29]. A case study of one subject after completing a 25-day ultra-endurance exercise challenge shows a slight reduction in FMD as long as $48 \mathrm{~h}$ after completion [16], and ultra-endurance exercise is also known to cause significantly increased levels of biomarkers for inflammation [30]. In the present study, we found increased levels of the endothelial adhesion molecules E-selectin, ICAM-1, and VCAM-1 after the Ironman distance triathlon, along with reduced FMD. These endothelial adhesion molecules are upregulated due to inflammation [25], but can also be modulated by increased shear stress [31]. There is evidence from cardiovascular disease patients of an inverse correlation between E-selectin levels and FMD-response [32] supporting a possible direct effect between the adhesion molecules and the reduced FMD. On the other hand, increased levels of E-selectin, ICAM-1, and VCAM-1 were demonstrated after the Oslo Marathon [33] and in another study, the researchers found no decrease in brachial FMD after the London Marathon [6], suggesting a lack of direct effect between the endothelial adhesion molecules and FMD. However, both of these studies were conducted after marathons with primary usage of only the lower body as discussed above. We measured circulating levels of soluble endothelial adhesion molecules, and we do not know in which part of the arterial tree these molecules are expressed. We assume that there is a larger accumulated dose of shear stress in the brachial artery after a triathlon than after a marathon due to the nature of the upper body's usage in triathlons [28]. Therefore, it is possible that increased expression of the adhesion molecules locally in the brachial artery can partly explain the reduced FMD observed in our study. Endothelial inflammation causes reduced NO-secretion through cytokine-stimulated intracellular production of reactive oxygen species (ROS) that reacts with NO, known as NOS-uncoupling [34]. FMD is partly NO-dependent [4] and reduced levels of NO could therefore explain the reduced FMD response in a state with endothelial inflammation. A recent article showed significantly increased ROS production rates in capillary blood after completing an ironman distance triathlon [35], supporting this hypothesis.

Reduced circulating L-arginine levels could offer a mechanistic explanation for the reduced FMD-response upon completion of the race. Vascular endothelial cells synthesize NO from L-arginine by NO synthase (NOS) [24,31], predominantly through endothelial NOS (eNOS) in endothelial cells [36]. The $\mathrm{K}_{\mathrm{m}}$ (concentration at which the reaction rate is half of its maximal value) is $2.9 \mu \mathrm{M}$ for purified eNOS [37], which is far less than the observed 35.8 (34.3-38.1) $\mu \mathrm{M}$. However, experiments on living bovine endothelial cells show that L-arginine uptake into the intracellular compartment containing eNOS is a limiting factor and demonstrate $a K_{m}$ of $29 \pm 6 \mu \mathrm{M}$ calculated by extracellular Larginine levels effect on intracellular eNOS activity [38]. Assuming similar circulating and extracellular levels of L-arginine, this puts measured circulating levels after the race within the range one can expect to be significant for intracellular eNOS activity. There are several studies of the effect of increased circulating L-arginine through food supplements on FMD with varying results ranging from no effect on FMD $[39,40]$ to improved FMD [41-43] and varying effects dependent on baseline values in overweight adults [44]. All of these studies [39-44] examine the effects of increased L-arginine from values around 50-120 $\mu \mathrm{M}$ 
at baseline in different populations with further increased values after using supplements. Therefore, one would expect less significance for NO production at these concentrations based on the in vitro studies of the $\mathrm{K}_{\mathrm{m}}$ for eNOS [38]. There are no studies to our awareness that examine FMD with acutely reduced L-arginine, as seen in our study. Therefore, we believe it is possible that reduced levels of L-arginine below levels of $40 \mu \mathrm{M}$, as seen in our study, could partly explain impaired endothelial function as measured with reduced FMD.

In addition to increased endothelial inflammation and reduced L-arginine levels, other possible mechanisms not evaluated in the present study might reduce FMD post-exercise. These include increased sympathetic activity $[45,46]$ and variations due to measurements at different times of the day [47]. Both baseline diameter [48] and altered flow stimulus [49] can alter the FMD response. However, we did not find any significant differences in baseline diameter or flow between the measurement times.

One week after the race, we found VCAM- 1 to be slightly reduced compared to baseline, while there was no significant change between baseline and the measurement one week after for FMD, ICAM-1, E-selectin, and L-arginine. We do not have a biochemical answer for the reduced VCAM-1 levels one week after the race. There is no international reference for VCAM-1, but the producer of the ELISA kits reports a standard range of 350-990 ng/mL for VCAM-1, and the levels one week after the race were within these limits. A limitation in the present study is the relatively small sample size, making it possible that there were other minor changes after the race that we did not find statistically significant due to a lack of statistical power. However, the more considerable changes found immediately after the race was not present one week later.

The significantly reduced endothelial function with increased endothelial inflammation and reduced L-arginine bioavailability was transient. Therefore, there was no evidence of any long-lasting reduced endothelial function after an Ironman triathlon from our study. However, it was previously proposed that there may be a U-shaped effect of exercise on endothelial function over time. It was proposed that moderate to high levels of exercise have a beneficial effect on endothelial function while both lack of exercise and extreme levels of exercise cause impaired endothelial function in otherwise healthy individuals [50]. Supporting this thesis there is evidence of an increased prevalence of subclinical coronary artery calcification and plaques in male long-distance runners compared to matched controls [51,52]. Therefore, we suggest that repeated episodes of transient endothelial inflammation and reduced endothelial function, such as demonstrated in this study, might be a part of the pathogenesis for the development of arterial calcification in long-distance endurance athletes.

\section{Conclusions}

The reduced FMD and L-arginine levels found immediately after completing the Norseman Xtreme triathlon were normalized one week after. In parallel, there was an altered endothelial inflammation that might in part explain the altered endothelial function.

Supplementary Materials: The following are available online at https://www.mdpi.com/article/10 .3390 / sports9060086/s1, S1: Raw data. CSV-file containing the raw data from the research.

Author Contributions: Conceptualization, C.N., H.S.M., J.M. and J.H.; methodology, C.N., H.S.M. and I.S.; formal analysis, C.N. and H.S.M.; investigation, C.N., H.S.M., M.B.-S. and I.S.; data curation, C.N. and H.S.M.; writing-original draft preparation, C.N.; writing-review and editing, C.N., H.S.M., M.B.-S., J.M., I.S. and J.H.; visualization, C.N.; supervision, J.H.; project administration, C.N., J.M. and J.H.; funding acquisition, J.H. All authors have read and agreed to the published version of the manuscript.

Funding: This study was funded through a grant form Aker BioMarine Antarctic AS (http:/ / www. akerbiomarine.com/, accessed on 21 May 2017).

Institutional Review Board Statement: The Regional Committee for Medical and Health Research Ethics in Norway (REC) approved all experimental measurements (reference: 2016/932), and the 
study was conducted according to the Declaration of Helsinki. All participants gave written informed consent.

Informed Consent Statement: Informed consent was obtained from all subjects involved in the study.

Data Availability Statement: The data presented in this study are openly available in the Supplemental Information as S1. Race times and the age of the subjects are omitted in the raw data to ensure anonymity for the subjects, as the race results are public.

Acknowledgments: This study was conducted by the Norseman Research team. The Norseman Research team consists of scientists from serval institutions furthering the knowledge of extreme endurance exercise in cooperation with the Norseman Xtreme Triathlon and volunteering participants.

Conflicts of Interest: The authors declare no conflict of interest. The funders had no role in the design of the study; in the collection, analyses, or interpretation of data; in the writing of the manuscript, or in the decision to publish the results.

\section{References}

1. Celermajer, D.S.; Sorensen, K.E.; Bull, C.; Robinson, J.; Deanfield, J.E. Endothelium-dependent dilation in the systemic arteries of asymptomatic subjects relates to coronary risk factors and their interaction. J. Am. Coll. Cardiol. 1994, 24, 1468-1474. [CrossRef]

2. Pohl, U.; Holtz, J.; Busse, R.; Bassenge, E. Crucial role of endothelium in the vasodilator response to increased flow in vivo. Hypertension 1986, 8, 37-44. [CrossRef] [PubMed]

3. Li, Y.S.; Haga, J.H.; Chien, S. Molecular basis of the effects of shear stress on vascular endothelial cells. J. Biomech. 2005, 38, 1949-1971. [CrossRef] [PubMed]

4. Green, D.J.; Dawson, E.A.; Groenewoud, H.M.; Jones, H.; Thijssen, D.H. Is flow-mediated dilation nitric oxide mediated? A meta-analysis. Hypertension 2014, 63, 376-382. [CrossRef]

5. Birk, G.K.; Dawson, E.A.; Batterham, A.M.; Atkinson, G.; Cable, T.; Thijssen, D.H.; Green, D.J. Effects of exercise intensity on flow mediated dilation in healthy humans. Int. J. Sports Med. 2013, 34, 409-414. [CrossRef] [PubMed]

6. Dawson, E.A.; Whyte, G.P.; Black, M.A.; Jones, H.; Hopkins, N.; Oxborough, D.; Gaze, D.; Shave, R.E.; Wilson, M.; George, K.P.; et al. Changes in vascular and cardiac function after prolonged strenuous exercise in humans. J. Appl. Physiol. 2008, 105, 1562-1568. [CrossRef]

7. De Oliveira, G.V.; Mendes Cordeiro, E.; Volino-Souza, M.; Rezende, C.; Conte-Junior, C.A.; Silveira Alvares, T. Flow-Mediated Dilation in Healthy Young Individuals Is Impaired after a Single Resistance Exercise Session. Int. J. Environ. Res. Public Health 2020, 17, 5194. [CrossRef]

8. Hwang, I.C.; Kim, K.H.; Choi, W.S.; Kim, H.J.; Im, M.S.; Kim, Y.J.; Kim, S.H.; Kim, M.A.; Sohn, D.W.; Zo, J.H. Impact of acute exercise on brachial artery flow-mediated dilatation in young healthy people. Cardiovasc. Ultrasound 2012, 10, 39. [CrossRef] [PubMed]

9. Kapilevich, L.V.; Kologrivova, V.V.; Zakharova, A.N.; Mourot, L. Post-exercise Endothelium-Dependent Vasodilation Is Dependent on Training Status. Front. Physiol. 2020, 11, 348. [CrossRef]

10. McClean, C.; Harris, R.A.; Brown, M.; Brown, J.C.; Davison, G.W. Effects of Exercise Intensity on Postexercise Endothelial Function and Oxidative Stress. Oxid. Med. Cell. Longev. 2015, 2015, 723679. [CrossRef] [PubMed]

11. Rakobowchuk, M.; Harris, E.; Taylor, A.; Baliga, V.; Cubbon, R.M.; Rossiter, H.B.; Birch, K.M. Heavy and moderate interval exercise training alters low-flow-mediated constriction but does not increase circulating progenitor cells in healthy humans. Exp. Physiol. 2012, 97, 375-385. [CrossRef] [PubMed]

12. Rognmo, O.; Bjornstad, T.H.; Kahrs, C.; Tjonna, A.E.; Bye, A.; Haram, P.M.; Stolen, T.; Slordahl, S.A.; Wisloff, U. Endothelial function in highly endurance-trained men: Effects of acute exercise. J. Strength Cond. Res. 2008, 22, 535-542. [CrossRef] [PubMed]

13. Shenouda, N.; Skelly, L.E.; Gibala, M.J.; MacDonald, M.J. Brachial artery endothelial function is unchanged after acute sprint interval exercise in sedentary men and women. Exp. Physiol. 2018, 103, 968-975. [CrossRef] [PubMed]

14. Tinken, T.M.; Thijssen, D.H.; Black, M.A.; Cable, N.T.; Green, D.J. Time course of change in vasodilator function and capacity in response to exercise training in humans. J. Physiol. 2008, 586, 5003-5012. [CrossRef]

15. Tjonna, A.E.; Rognmo, O.; Bye, A.; Stolen, T.O.; Wisloff, U. Time course of endothelial adaptation after acute and chronic exercise in patients with metabolic syndrome. J. Strength Cond. Res. 2011, 25, 2552-2558. [CrossRef] [PubMed]

16. Tiller, N.B.; Chiesa, S.T.; Roberts, J.D.; Turner, L.A.; Jones, S.; Romer, L.M. Physiological and Pathophysiological Consequences of a 25-Day Ultra-Endurance Exercise Challenge. Front. Physiol. 2019, 10, 589. [CrossRef]

17. Dawson, E.A.; Green, D.J.; Cable, N.T.; Thijssen, D.H. Effects of acute exercise on flow-mediated dilatation in healthy humans. J. Appl. Physiol. 2013, 115, 1589-1598. [CrossRef] [PubMed]

18. Neubauer, O.; Konig, D.; Wagner, K.H. Recovery after an Ironman triathlon: Sustained inflammatory responses and muscular stress. Eur. J. Appl. Physiol. 2008, 104, 417-426. [CrossRef] [PubMed]

19. Danielsson, T.; Carlsson, J.; Schreyer, H.; Ahnesjo, J.; Ten Siethoff, L.; Ragnarsson, T.; Tugetam, A.; Bergman, P. Blood biomarkers in male and female participants after an Ironman-distance triathlon. PLoS ONE 2017, 12, e0179324. [CrossRef] 
20. Nyborg, C.; Melau, J.; Bonnevie-Svendsen, M.; Mathiasen, M.; Melsom, H.S.; Storsve, A.B.; Hisdal, J. Biochemical markers after the Norseman Extreme Triathlon. PLoS ONE 2020, 15, e0239158. [CrossRef] [PubMed]

21. Danielsson, T.; Schreyer, H.; Woksepp, H.; Johansson, T.; Bergman, P.; Mansson, A.; Carlsson, J. Two-peaked increase of serum myosin heavy chain-alpha after triathlon suggests heart muscle cell death. BMJ Open Sport Exerc. Med. 2019, 5, e000486. [CrossRef] [PubMed]

22. Carlsson, J.; Ragnarsson, T.; Danielsson, T.; Johansson, T.; Schreyer, H.; Breyne, A.; Bergman, P. Biochemical changes after strenuous exercise-Data from the Kalmar Ironman. Lakartidningen 2016, 113, 27483401.

23. Storsve, A.B.; Johnsen, L.; Nyborg, C.; Melau, J.; Hisdal, J.; Burri, L. Effects of Krill Oil and Race Distance on Serum Choline and Choline Metabolites in Triathletes: A Field Study. Front. Nutr. 2020, 7, 133. [CrossRef]

24. Palmer, R.M.; Ashton, D.S.; Moncada, S. Vascular endothelial cells synthesize nitric oxide from L-arginine. Nature 1988, 333, 664-666. [CrossRef] [PubMed]

25. Klein, C.L.; Kohler, H.; Bittinger, F.; Wagner, M.; Hermanns, I.; Grant, K.; Lewis, J.C.; Kirkpatrick, C.J. Comparative studies on vascular endothelium in vitro. I. Cytokine effects on the expression of adhesion molecules by human umbilical vein, saphenous vein and femoral artery endothelial cells. Pathobiology 1994, 62, 199-208. [CrossRef] [PubMed]

26. Kerns, W.; Schwartz, L.; Blanchard, K.; Burchiel, S.; Essayan, D.; Fung, E.; Johnson, R.; Lawton, M.; Louden, C.; MacGregor, J.; et al. Drug-induced vascular injury-a quest for biomarkers. Toxicol. Appl. Pharm. 2005, 203, 62-87. [CrossRef]

27. Hashimoto, M.; Akishita, M.; Eto, M.; Ishikawa, M.; Kozaki, K.; Toba, K.; Sagara, Y.; Taketani, Y.; Orimo, H.; Ouchi, Y. Modulation of endothelium-dependent flow-mediated dilatation of the brachial artery by sex and menstrual cycle. Circulation 1995, 92, 3431-3435. [CrossRef]

28. Del Coso, J.; Gonzalez-Millan, C.; Salinero, J.J.; Abian-Vicen, J.; Soriano, L.; Garde, S.; Perez-Gonzalez, B. Muscle damage and its relationship with muscle fatigue during a half-iron triathlon. PLoS ONE 2012, 7, e43280. [CrossRef]

29. Kim, H.J.; Lee, Y.H.; Kim, C.K. Changes in serum cartilage oligomeric matrix protein (COMP), plasma CPK and plasma hs-CRP in relation to running distance in a marathon $(42.195 \mathrm{~km})$ and an ultra-marathon $(200 \mathrm{~km})$ race. Eur. J. Appl. Physiol. 2009, 105, 765-770. [CrossRef]

30. Jee, H.; Park, J.; Oh, J.G.; Lee, Y.H.; Shin, K.A.; Kim, Y.J. Effect of a prolonged endurance marathon on vascular endothelial and inflammation markers in runners with exercise-induced hypertension. Am. J. Phys. Med. Rehabil. 2013, 92, 513-522. [CrossRef]

31. Chiu, J.J.; Lee, P.L.; Chen, C.N.; Lee, C.I.; Chang, S.F.; Chen, L.J.; Lien, S.C.; Ko, Y.C.; Usami, S.; Chien, S. Shear stress increases ICAM-1 and decreases VCAM-1 and E-selectin expressions induced by tumor necrosis factor-[alpha] in endothelial cells. Arter. Thromb. Vasc. Biol. 2004, 24, 73-79. [CrossRef] [PubMed]

32. Altun, I.; Oz, F.; Arkaya, S.C.; Altun, I.; Bilge, A.K.; Umman, B.; Turkoglu, U.M. Effect of statins on endothelial function in patients with acute coronary syndrome: A prospective study using adhesion molecules and flow-mediated dilatation. J. Clin. Med. Res. 2014, 6, 354-361. [CrossRef] [PubMed]

33. Nielsen, H.G.; Lyberg, T. Long-distance running modulates the expression of leucocyte and endothelial adhesion molecules. Scand. J. Immunol. 2004, 60, 356-362. [CrossRef] [PubMed]

34. Frey, R.S.; Ushio-Fukai, M.; Malik, A.B. NADPH oxidase-dependent signaling in endothelial cells: Role in physiology and pathophysiology. Antioxid. Redox Signal. 2009, 11, 791-810. [CrossRef]

35. Mrakic-Sposta, S.; Gussoni, M.; Vezzoli, A.; Dellanoce, C.; Comassi, M.; Giardini, G.; Bruno, R.M.; Montorsi, M.; Corciu, A.; Greco, F.; et al. Acute Effects of Triathlon Race on Oxidative Stress Biomarkers. Oxid. Med. Cell. Longev. 2020, 2020, 3062807. [CrossRef] [PubMed]

36. Garcia, V.; Sessa, W.C. Endothelial NOS: Perspective and recent developments. Br. J. Pharm. 2019, 176, 189-196. [CrossRef]

37. Pollock, J.S.; Forstermann, U.; Mitchell, J.A.; Warner, T.D.; Schmidt, H.H.; Nakane, M.; Murad, F. Purification and characterization of particulate endothelium-derived relaxing factor synthase from cultured and native bovine aortic endothelial cells. Proc. Natl. Acad. Sci. USA 1991, 88, 10480-10484. [CrossRef]

38. Hardy, T.A.; May, J.M. Coordinate regulation of L-arginine uptake and nitric oxide synthase activity in cultured endothelial cells. Free Radic. Biol. Med. 2002, 32, 122-131. [CrossRef]

39. Gates, P.E.; Boucher, M.L.; Silver, A.E.; Monahan, K.D.; Seals, D.R. Impaired flow-mediated dilation with age is not explained by L-arginine bioavailability or endothelial asymmetric dimethylarginine protein expression. J. Appl. Physiol. 2007, 102, 63-71. [CrossRef]

40. Blum, A.; Hathaway, L.; Mincemoyer, R.; Schenke, W.H.; Kirby, M.; Csako, G.; Waclawiw, M.A.; Panza, J.A.; Cannon, R.O., 3rd Oral L-arginine in patients with coronary artery disease on medical management. Circulation 2000, 101, 2160-2164. [CrossRef]

41. Bode-Boger, S.M.; Muke, J.; Surdacki, A.; Brabant, G.; Boger, R.H.; Frolich, J.C. Oral L-arginine improves endothelial function in healthy individuals older than 70 years. Vasc. Med. 2003, 8, 77-81. [CrossRef]

42. Clarkson, P.; Adams, M.R.; Powe, A.J.; Donald, A.E.; McCredie, R.; Robinson, J.; McCarthy, S.N.; Keech, A.; Celermajer, D.S.; Deanfield, J.E. Oral L-arginine improves endothelium-dependent dilation in hypercholesterolemic young adults. J. Clin. Investig. 1996, 97, 1989-1994. [CrossRef]

43. Yin, W.H.; Chen, J.W.; Tsai, C.; Chiang, M.C.; Young, M.S.; Lin, S.J. L-arginine improves endothelial function and reduces LDL oxidation in patients with stable coronary artery disease. Clin. Nutr. 2005, 24, 988-997. [CrossRef] [PubMed] 
44. Deveaux, A.; Pham, I.; West, S.G.; Andre, E.; Lantoine-Adam, F.; Bunouf, P.; Sadi, S.; Hermier, D.; Mathe, V.; Fouillet, H.; et al. L-Arginine Supplementation Alleviates Postprandial Endothelial Dysfunction When Baseline Fasting Plasma Arginine Concentration Is Low: A Randomized Controlled Trial in Healthy Overweight Adults with Cardiometabolic Risk Factors. J. Nutr. 2016, 146, 1330-1340. [CrossRef]

45. Gundersen, K.M.; Nyborg, C.; Heiberg Sundby, O.; Hisdal, J. The effects of sympathetic activity induced by ice water on blood flow and brachial artery flow-mediated dilatation response in healthy volunteers. PLoS ONE 2019, 14, e0219814. [CrossRef]

46. Gratze, G.; Rudnicki, R.; Urban, W.; Mayer, H.; Schlogl, A.; Skrabal, F. Hemodynamic and autonomic changes induced by Ironman: Prediction of competition time by blood pressure variability. J. Appl. Physiol. 2005, 99, 1728-1735. [CrossRef]

47. ter Avest, E.; Holewijn, S.; Stalenhoef, A.F.; de Graaf, J. Variation in non-invasive measurements of vascular function in healthy volunteers during daytime. Clin. Sci. 2005, 108, 425-431. [CrossRef]

48. Maruhashi, T.; Iwamoto, Y.; Kajikawa, M.; Oda, N.; Kishimoto, S.; Matsui, S.; Hashimoto, H.; Aibara, Y.; Yusoff, F.M.; Hidaka, T.; et al. Interrelationships Among Flow-Mediated Vasodilation, Nitroglycerine-Induced Vasodilation, Baseline Brachial Artery Diameter, Hyperemic Shear Stress, and Cardiovascular Risk Factors. J. Am. Heart Assoc. 2017, 7. [CrossRef]

49. Pyke, K.E.; Tschakovsky, M.E. The relationship between shear stress and flow-mediated dilatation: Implications for the assessment of endothelial function. J. Physiol. 2005, 568, 357-369. [CrossRef]

50. Durand, M.J.; Gutterman, D.D. Exercise and vascular function: How much is too much? Can. J. Physiol. Pharm. 2014, 92, 551-557. [CrossRef] [PubMed]

51. Merghani, A.; Maestrini, V.; Rosmini, S.; Cox, A.T.; Dhutia, H.; Bastiaenan, R.; David, S.; Yeo, T.J.; Narain, R.; Malhotra, A.; et al. Prevalence of Subclinical Coronary Artery Disease in Masters Endurance Athletes With a Low Atherosclerotic Risk Profile. Circulation 2017, 136, 126-137. [CrossRef] [PubMed]

52. Mohlenkamp, S.; Lehmann, N.; Breuckmann, F.; Brocker-Preuss, M.; Nassenstein, K.; Halle, M.; Budde, T.; Mann, K.; Barkhausen, J.; Heusch, G.; et al. Running: The risk of coronary events: Prevalence and prognostic relevance of coronary atherosclerosis in marathon runners. Eur. Heart J. 2008, 29, 1903-1910. [CrossRef] [PubMed] 